\title{
ASSISTÊNCIA DE ENFERMAGEM NOS HOSPITAIS PSIQUIÁTRICOS DO MUNICÍPIO DE SÃO PAULO
}

\author{
* Evalda Cançado Arantes
}

A falta de dados sobre os hospitais psiquiátricos existentes no Município de São Paulo, levou-nos à realização de um levantamento que nos forneceu informações sobre os serviços de enfermagem dos mesmos.

O levantamento completo foi muito extenso porque destinava-se a colher dados para a execução de uma tese de doutoramento. Julgamos, entretanto, que respostas a algumas indagaçōes, que sempre nos fizemos, poderiam ser de utilidade para pessoas também interessadas no assunto. Assim sendo o presente trabalho foi elaborado com a finalidade de fornecer respostas às seguintes indagaçōes:

1. Quantos hospitais psiquiátricos estão funcionando no município de São Paulo?

2. Quais as categorias de pessoal de enfermagem que neles estão trabalhando?

3. Que preparo esse pessoal recebeu para trabalhar em hospital psiquiátrico?

4. Quem se encarrega de fazer o preparo do pessoal de enfermagem?

5. Quais são as atividades atuais do pessoal de enfermagem predominante nos hospitais?

\section{MÉTODO}

A técnica utilizada no presente estudo foi a da entrevista.

Preliminarmente foi realizada a localização dos hospitais do Município de São Paulo para delimitar a população do estudo. A seguir foram feitas entrevistas com diretores, administradores ou pessoas designadas pela direção do hospital para fornecer os dados,

* Professora da disciplina Enfermagem Psiquiátrica da Escola de Enfermagem da USP. 
por nós solicitados, sobre o hospital e seu serviço de enfermagem. Posteriormente foram realizadas entrevistas com atendentes que foram objeto de estudo especial (1).

\section{RESULTADOS e COMENTÁRIOS}

Foram localizados 27 hospitais psiquiátricos, em funcionamento, no Município de São Paulo, e obtivemos dados referentes a 25 deles. Foi-nos permitido entrevistar 74 atendentes, de 19 hospitais, durante seu período de trabalho, no turno da manhã.

Dos 27 hospitais existentes 5 são públicos (governamentais e autárquicos) e 22 são privados (lucrativos e filantrópicos). Os dados obtidos referem-se a 5 hospitais públicos e a 20 hospitais privados.

No quadro 1 podemos ver que $92,7 \%$ dos leitos disponíveis estavam sendo ocupados por pacientes que recebiam tratamento psiquiátrico.

QUADRO 1 - CAPACIDADE E NÚMERO DE PACIENTES INTER-

NADOS EM 25 HOSPITAIS DO MUNICÍPIO DE SÃO PAULO

HOSPITAIS CAPACIDADE

N.o

1.785

3.519

5.304
1.703

3.215

4.918
95,4

91,4

TOTAL

Para o atendimento de 5.304 pacientes os hospitais contavam com 926 pessoas nos seus serviços de enfermagem, como está evidente no Quadro 2. Nessa situação temos a relação de 1 pessoa da enfermagem para 5,7 leitos, nas 24 horas de serviço.

* O total de pacientes internados foi conseguido com a soma dos pacientes internados no hospital, no dia em que o levantamento foi reaIizado, no período abrangido entre setembro e novembro de 1972.

(1) População de estudo. por nós realizado, sobre observação de comportamento. 


\section{QUADRO 2 - PESSOAL DE ENFERMAGEM EXISTENTE NOS HOSPITAIS PÚBLICOS E PRIVADOS PARA AS 24 HORAS DE SERVIÇO}

\begin{tabular}{|c|c|c|c|c|c|c|}
\hline \multirow{2}{*}{$\begin{array}{l}\text { CATEGORIA } \\
\text { DO PESSOAL }\end{array}$} & \multicolumn{2}{|c|}{ PÚBLICOS } & \multicolumn{2}{|c|}{ PRIVADOS } & \multicolumn{2}{|c|}{ TOTAL } \\
\hline & N.o & $\%$ & N.o & $\%$ & N. ${ }^{\circ}$ & $\%$ \\
\hline Enfermeiros & 23 & 5,7 & 8 & 1,5 & 31 & 3,3 \\
\hline $\begin{array}{l}\text { Auxiliares de } \\
\text { Enfermagem }\end{array}$ & 59 & 14,6 & 40 & 7,7 & 99 & 10,7 \\
\hline $\begin{array}{l}\text { Práticos de } \\
\text { Enfermagem }\end{array}$ & 3 & 0,7 & 20 & 3,8 & 23 & 2,5 \\
\hline Atendentes & 184 & 45,6 & 311 & 59,6 & 495 & 53,5 \\
\hline Serventes & 135 & 33,4 & 143 & 27,4 & 278 & 30,0 \\
\hline TOTAL & 404 & 100,0 & 522 & 100,0 & 926 & 100,0 \\
\hline
\end{tabular}

Havia 8 enfermeiros trabalhando em 7 dos hospitais privados $(35,0 \%)$ e, evidentemente, 13 deles $(65,0 \%)$ não contavam com enfermeiras nem para a direção do serviço de enfermagem. Nos hospitais privados a relação era de 1 pessoa da enfermagem para 6,8 pacientes. Os atendentes e serventes representavam 83,5\% (773) do pessoal de enfermagem, dos hospitais públicos e privados, enquanto as enfermeiras representavam $3,3 \%$ (31) e os auxiliares e práticos de Enfermagem 13,2\% (122).

Nos hospitais públicos a situação era muito diversa. No Quadro 3 os mesmos foram individualizados para melhor objetivação da situação presente.

* Deste pessoal foram excluidos barbeiros, auxiliares de médico e escriturários, que apesar de estarem subordinados ao serviço de enfermagem, tinham funções definidas e diferentes das demais pessoas naquele serviço. 
QUADRO 3 - NÚMERO DE PESSOAL DE ENFERMAGEM

NOS HOSPITAIS (5) E RELAÇÃO PESSOAL/

LEITO NOS CINCO HOSPITAIS

HOSPITAIS PÚBLICOS

(1.785 leitos)

\begin{tabular}{|c|c|c|c|c|c|c|}
\hline \multirow{3}{*}{ PESSOAL } & \multirow{3}{*}{$\begin{array}{c}1009 \text { leitos } \\
\text { N. }{ }^{\circ}\end{array}$} & B & C & $\mathbf{D}$ & $\mathbf{E}$ & \\
\hline & & \multirow{2}{*}{$\begin{array}{c}300 \text { leitos } \\
\text { N. }\end{array}$} & 191 leitos & 42 leitos & \multicolumn{2}{|c|}{243 leitos } \\
\hline & & & N. ${ }^{\circ}$ & N. ${ }^{\circ}$ & N. ${ }^{\circ}$ & TOTAL N. ${ }^{\circ}$ \\
\hline & & c & & & & \\
\hline Enfermeiros & 1 & - & 1 & 3 & 18 & 23 \\
\hline \multicolumn{7}{|l|}{ Auxiliares de } \\
\hline Enfermagem & 5 & 3 & 7 & 8 & 36 & 59 \\
\hline \multicolumn{7}{|l|}{ Práticos de } \\
\hline Enfermagem & - & - & - & - & 3 & 3 \\
\hline Atendentes & 49 & 26 & 14 & 14 & 81 & 184 \\
\hline Serventes & 87 & 28 & 20 & - & - & 135 \\
\hline TOTAL & 142 & 57 & 42 & 25 & 138 & 404 \\
\hline \multicolumn{7}{|l|}{ RELAÇĀO } \\
\hline PESSOAL/LEITO & 7,1 & 5,3 & 4,5 & 1,7 & 1,8 & 4.4 \\
\hline
\end{tabular}

Assim podemos evidenciar que 78,3\% (18) dos enfermeiros, dos hospitais públicos, estão concentrados em um só hospital quando em um deles não há sequer um enfermeiro para a direção do serviço de enfermagem.

A situação dos hospitais, quanto à direção do serviço de enfermagem, está expressa no Quadro 4. 
QUADRO 4 - DIREÇÃO DOS SERVIÇOS DE ENFERMAGEM EM 25 HOSPITAIS DO MUNICÍPIO DE SÃO PAULO

HOSPITAIS

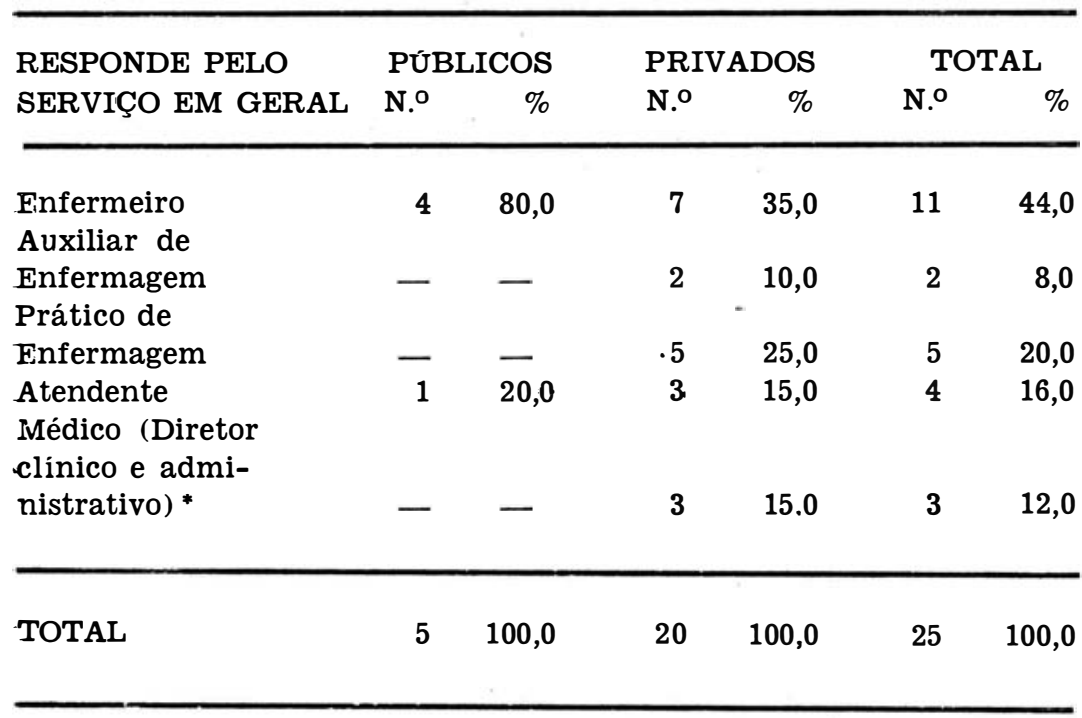

Os atendentes e serventes são admitidos, por concurso público, nos hospitais governamentais e, em geral, por simples entrevista nos hospitais privados. No presente estudo foram contados, no pessoal de enfermagem, apenas os serventes que prestam cuidados aos pacientes e, quando fizemos as entrevistas, todos foram considerados atendentes.

Os atendentes deveriam receber treinamento em serviço. As informaçōes que obtivemos, contudo, evidenciam que em 52,0\% (13) hospitais declaram ter um programa de orientação para o pessoal recém admitido, sendo o citado programa desenvolvido por:

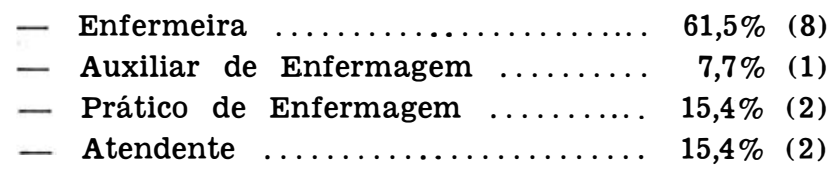

* Na presente situação, existe um responsável pelas unidades masculinas e uma responsável pelas unidades femininas. Nos três hospitais encarregados de suas respectivas unidades 2 práticos de enfermagem e 4 atendentes. 
Os enfermeiros (8) que fazem orientação dos recém admitidos. citaram como conteúdo de seus programas 17 assuntos que são os: seguintes, obedecendo a frequência em que os mesmos aparecem:

- Noçōes sobre o funcionamento do hospital (4)

- Rotinas (3)

- Técnicas de enfermagem (2)

- Noções básicas de enfermagem geral (2)

- Relacionamento com pacientes (2)

- Noções básicas de enfermagem psiquiátrica (1)

- Preparo de medicação (1)

- Restrições (1)

Como pode ser observado, mesmo quando a orientação é feita por enfermeiros o conteúdo de enfermagem psiquiátrica, aqui representado por "Noçōes básicas de enfermagem psiquiátrica" e "Relacionamento com pacientes", aparece apenas 3 vezes o que representa $17,6 \%$ dos assuntos citados (17).

Nos restantes 5 hospitais, onde a orientação é feita por auxiliar de enfermagem (1), práticos de enfermagem (2) e atendentes (2), o conteúdo da mesma é o que segue:

Função do atendente dentro do hospital (4)

Orientação de como agir (4)

Como atender o doente (2)

Alimentação (1)

Higiene (1)

Em 80,0\% (20) dos hospitais não há um programa de ensino ou atualização para o pessoal antigo. Em 20,0\% (5) dos hospitais há programas regulares de atualização e orientação de seu pessoal de enfermagem, sendo o ensino ministrado por médico (1), enfermeiros (3) e médico e enfermeiro (1).

Para o presente estudo utilizamos as entrevistas realizadas com 74 atendentes de 5 hospitais públicos e 14 privados. Desses atendentes $8(10,8 \%)$ declararam não ter recebido qualquer orientação ao começar o trabalho no hospital. Os demais $89,2 \%$ (66) receberam orientação inicial sobre o trabalho no hospital e citaram

dades para as quais foram orientados. A média de atividades desenvolvidas pelos atendentes foi 1,7. As 114 atividades que foram citadas podem ser reunidas em quatro áreas.

1 - Funcionamento do serviço compreendendo regulamento do hospital, convênios, tipo de serviço esperado do atendente e horário de trabalho. 
2 - Ordem e limpeza que consiste em arrumação de camas, limpeza de unidade e ordem no vestiário.

3 - Atenção aos pacientes: banho no leito, cuidados no pós operatório, conversação com pacientes, como dar alimentação, cuidados com pacientes agressivos, como fazer contensōes, restriçōes e vigilância; cuidado com objetos perigosos; suicídio; fuga; noções sobre doenças e anotações.

4 - Técnicas especiais: tratamentos por eletrochoque, por insulina e por psicotrópicos; sinais vitais, curativos, medicação oral e medicação injetável.

Os 66 atendentes informaram haver recebido orientação das seguintes pessoas:

\begin{tabular}{|c|c|c|}
\hline Enfermeiras & 23 & $(34,8 \%)$ \\
\hline Atendentes & 14 & $(21,2 \%)$ \\
\hline Auxiliares de enfermagem & 10 & $(15,2 \%)$ \\
\hline Médicos $\ldots \ldots \ldots \ldots \ldots$ & 7 & $(10,6 \%)$ \\
\hline Práticos de enfermagem & 6 & $(9,1 \%)$ \\
\hline Administradores $\ldots \ldots \ldots$ & 5 & $(7,6 \%)$ \\
\hline Terapêuta ocupacional & 1 & $(1,5 \%)$ \\
\hline Total & 66 & $(100,0 \%)$ \\
\hline
\end{tabular}

Após a orientação inicial, 28,4\% (21) dos atendentes negaram haver recebido qualquer treinamento em serviço e $71,6 \%$ (53) afirmaram haver recebido treinamento em serviço sob a orientação de:

\begin{tabular}{|c|c|c|}
\hline Atendentes & 32 & $(60,4 \%)$ \\
\hline Enfermeiras .. & 12 & $(22,7 \%)$ \\
\hline Auxiliares de enfermagem & 4 & $(7,5 \%)$ \\
\hline Práticos de enfermagem . & 4 & $(7,5 \%)$ \\
\hline Médico & 1 & $(1,9 \%)$ \\
\hline Total & 53 & $(100,0 \%)$ \\
\hline
\end{tabular}

Temos a considerar, ainda, que o período de orientação é curto : que, na maioria dos hospitais, não vai além da recepção do atendente, no dia em que começa a trabalhar.

Os 74 atendentes entrevistados estavam exercendo suas funções em tempo que variava de 2 semanas a 25 anos, sendo que $59,4 \%$ (44) dos mesmos contavam menos de cinco anos de trabalho e, $243 \%$ (18) contavam menos de um ano de serviço. Todos estavam exercendo suas atividades junto aos pacientes e citaram 346 atividades por eles exercidas, habitualmente. Com a descrição do trabalho por eles executado foi feito o agrupamento das atividades citadas, da mesma forma que para a orientação recebida. 
1. Funcionamento do serviço: responsável pela unidade, atende o médico, transcreve prescrição médica, faz distribuição do serviço, relatórios de ocorrências, controle do material, atende a porta e faz remoção de pacientes.

2. Ordem e limpeza: ordem nos quartos e vestiários, limpeza geral, limpeza de unidade e da sala de serviço.

3. Atenção aos pacientes: conversa com pacientes, mantém recreação e atividades para os pacientes, providencia sua alimentação, provê condições para o banho, faz admissão de pacientes e os acompanha em suas saídas da unidade; auxilia nos tratamentos psiquiátricos, cuida dos pacientes impregnados e acamados, faz anotações e observa pacientes em situação especial.

4. Técnicas especiais: faz medicação, curativos e colheita de material para exames de laboratório; controla sinais vitais e aplica tratamentos como eletrochoqueterapia e insulinoterapia.

A média de atividades exercidas por atendente foi de 4,8.

Como pode ser evidenciado nos dados citados, os atendentes estão exercendo atividades de enfermagem que vão muito além de suas condições de conhecimento e preparo. No Quadro 5 nós fazemos uma comparação entre o número de orientações recebidas e o número de atividades que estão exercendo.

QUADRO 5 - NÚMERO DE ATIVIDADES PARA AS QUAIS 66 ATENDENTES FORAM ORIENTADOS E 74 ATENDENTES ESTAVAM EXECUTANDO - SETEMBRO A NOVEMBRO DE 1972

\section{ATIVIDADES}

ÁREA DE ATIVIDADE FORAM ORIENTADAS ESTÃO FAZENDO DE ENFERMAGEM (66 atendentes)

(74 atendentes)

N. $\quad$ \% $\quad$ N. $\quad \%$

1. Funcionamento

$\begin{array}{lllll}\text { do hospital } & 21 & 18,4 & 50 & 14,4\end{array}$

2. Ordem e limpeza

$\begin{array}{lllll}\text { do ambiente } & 26 & 22,8 & 35 & 10,1\end{array}$

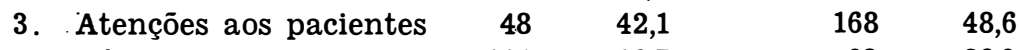

$\begin{array}{lllll}\text { 4. Técnicas especiais* } & 114 & 16,7 & 93 & 26,9\end{array}$

\begin{tabular}{lllll}
\hline TOTAL & 114 & 100,0 & 346 & 100,0 \\
\hline
\end{tabular}

* Neste grupo estão incluídos eletrochoque e insulinoterapia. 
A média das atividades orientadas é 1,7 e a média das atividades executadas é 4,8 , por atendente.

Desse grupo de atendentes apenas $18,9 \%$ (14) têm funções definidas, como atendentes, e não dão e nem virão a aplicar medicacão, a menos que façam o Curso de Auxiliar de Enfermagem. Os demais, provavelmente, irão fazer de tudo como os mais antigos.

A situação da assistência de enfermagem, nos hospitais psiquiátricos do Município de São Paulo, ainda deixa muito a desejar. Gostaríamos de ressaltar, aqui, que não tencionamos acusar os atendentes pela situação existente. Reconhecemos o esforço feito por eles para trabalhar da melhor maneira possivel e, se cometem falhas, estas são decorrentes da sua falta de preparo para trabalhar com doentes mentais. 